\title{
El declive del Estado moderno y la metamorfosis del lus Publicum Ecclesiasticum
}

\section{The Decline of the Modern State and the Transformation of the lus Publicum Ecclesiasticum}

\section{Giuseppe DALla TORRE}

Profesor Emérito de Derecho Canónico y Eclesiástico Libera Università Maria ss. Assunta - LUMSA. Roma dallatorre@lumsa.it

Resumen: En este artículo se indaga acerca de la incidencia que el declive del Estado moderno tiene sobre la metamorfosis del lus Publicum Ecclesiasticum Externum: una disciplina nacida con el surgimiento, a fines de la Edad Media, de una peculiar forma de organización política que llamamos, precisamente, Estado moderno. Se analiza el proceso de nacimiento y desarrollo del Estado, fundado principalmente sobre el concepto de soberanía. La Iglesia hizo frente a este fenómeno mediante el desarrollo del lus Publicum Ecclesiasticum Externum. La actual decadencia del Estado se estima consecuencia, entre otros factores, de la globalización y del fin del concepto de soberanía. Estas circunstancias propician la metamorfosis del lus Publicum, que tiende a adoptar una visión universalista orientada hacia la tutela de los derechos humanos y hacia la consideración de la Iglesia como Pueblo de Dios, abriendo mayores espacios a la acción de los laicos en la animación de cristiana del orden temporal.

Palabras clave: Ius Publicum Ecclesiasticum, Estado moderno, Soberanía, libertas Ecclesiae, iura nativa Ecclesiae, Derechos humanos, Libertad religiosa.
Abstract: This paper explores the impact of the decline of the modern state on the transformation of the lus Publicum Ecclesiasticum Externum, a discipline that emerged alongside the rise in the late Middle Ages of a particular form of political organization known as the modern state. It analyzes the process by which the modern state emerged and developed, based primarily on the concept of sovereignty. The Church addressed this phenomenon through the development of the lus Publicum Ecclesiasticum Externum. Amongst other factors, globalization and the eclipse of the concept of sovereignty are expected to lead to the decline of the modern state. These circumstances favor the transformation of the lus Publicum, which tends to offer a universal vision that favors the protection of human rights and views the Church as a People of God, opening a greater space in which laypeople may foster the Christian spirit in the temporal order.

Keywords: Ius Publicum Ecclesiasticum, Modern State, Sovereignty, libertas Ecclesiae, iura nativa Ecclesiae, Human Rights, Religious Freedom. 


\section{GIUSEPPE DALLA TORRE}

\section{INTRODUCCIÓN}

E n un importante trabajo sobre la monarquía papal en la primera edad moderna, un gran historiador italiano recientemente desaparecido, Paolo Prodi, escribía: «la conciencia de la crisis del Estado moderno también en sus últimas encarnaciones y el desarrollo del interés por la recuperación de un discurso de autonomía de la esfera de lo social, ya no desde un punto de vista retrospectivo y medieval, lleva a nuevas perspectivas: superada la Edad de la Contrarreforma, estamos también saliendo del eón del Estado moderno como expresión del individualismo político y del monopolio de la fuerza y del ordenamiento jurídico» ${ }^{1}$.

Estas consideraciones fueron escritas como conclusión de una mesurada y documentadísima investigación sobre el papel del Papado en la construcción del sistema europeo de Estados en el momento del hundimiento de la Respublica Christiana medieval y sobre el paradigma constituido por el Estado pontificio para los Estados modernos. Son consideraciones que se prestan bien a introducir las reflexiones que se quieren proponer, dirigidas a indagar, aunque sea a través de retazos y fragmentos, la incidencia que la decadencia del Estado moderno presente ante nuestros ojos viene a tener sobre la metamorfosis del Ius Publicum Ecclesiasticum Externum: una disciplina nacida justamente con el surgimiento, a fines de la Edad Media, de una peculiar forma de organización política que llamamos, precisamente, Estado moderno, muy diferente si se lo compara con la pluralidad de formas que habían asumido antes las instituciones políticas.

En efecto, el problema de las relaciones entre la Iglesia y el poder político es una cuestión de siempre: lo han conocido bien la Edad Antigua y la Edad Media $^{2}$; no obstante, dicho problema asumió formas peculiares con la modernidad. El Derecho canónico siempre se ha visto afectado por la cuestión, pero únicamente en la Edad Moderna, ante el ascenso de la forma-Estado, ha sido objeto de una reflexión específica, dando precisamente vida a ese sector del saber que es el Ius Publicum. Por tanto, es legítimo plantearse el problema: ¿el ocaso del Estado moderno está destinado a señalar también el ocaso del Ius Publicum?; ¿¿, al menos, a provocar incisivas metamorfosis?

${ }^{1}$ P. Prodi, Il Sovrano Pontifice. Un corpo e due anime: la monarchia papale nella prima età moderna, Il Mulino, Bologna 2006, 352.

2 Siempre es útil al respecto la lectura de las páginas de G. B. Guzzetri, Chiesa e política. Disegno storico, Marietti, Torino 1975. Para las tentaciones del poder político en las Edades Antigua y medieval cfr. la voz de J. Calvo Álvarez, Cesaropapismo, en Diccionario General de Derecho Canónico, dirigido por J. OtaduY - A. Viana - J. Sedano, vol. II, Aranzadi, Cizur Menor 2012, 69 ss. 
Que las metamorfosis se están produciendo, aunque no siempre de forma claramente perceptible, lo indica un dato formal pero incontrovertible: el Ius Publicum continúa subsistiendo como sector del Derecho canónico, tanto desde el punto de vista normativo como doctrinal, pero sin embargo la denominación tradicional casi ha desaparecido, sin que haya sido sustituida por otra generalmente aceptada por los cultivadores de la disciplina ${ }^{3}$. Personalmente, en el volumen que en cierto modo retoma y reasume toda una vida de investigación sobre el asunto, he preferido recurrir, para el título, a una metáfora de ascendencia agustiniana: La città sul monte ${ }^{4}$. Una metáfora sugerente, pero que a su vez ha exigido una precisión descriptiva, esto es, que se trataba de una «contribución a una teoría canonística de las relaciones entre la Iglesia y la Comunidad política».

La lectura común a propósito de la desaparición de la denominación misma de Ius Publicum, así como como de la transformación de sus contenidos, se remonta a los efectos del Concilio Vaticano II: piénsese únicamente en la crítica de la categoría antigua, constitutiva de toda la concepción iuspublicística canónica, de la Iglesia como societas iuridice perfecta, en las obras de la canonística posconciliar ${ }^{5}$. Una lectura comprensible y que sustancialmente se puede compartir, también si los estudiosos de esta materia se valen de una operación, hasta cierto punto puramente transformista, por la que sustituyen la calificación de la Iglesia como societas perfecta con la calificación del ordenamiento canónico como ordenamiento jurídico primario, originario, soberano ${ }^{6}$.

\footnotetext{
${ }^{3}$ Para confirmar cuanto se ha escrito más arriba, baste una sucinta referencia a algunos textos aparecidos después del Concilio: G. SARACENI, Chiesa e comunità política, Giuffré, Milano 1983; G. LeZIRoli, Stato e Chiesa. Per una storia del dualismo giuridizionale cristiano, Giappichelli, Torino 1991; IDEM, Relazioni fra Chiesa cattolica e potere politico, La religione come limite del potere, Giappichelli, Torino ${ }^{4} 1998$; V. PRIETO, Diritto dei rapporti tra Chiesa e società civile, Edizioni Università della Santa Croce, Roma 2003; R. MinneraTH, L'Église catholique face aux États. Deux siècles de pratique concordataire 1801-2010, Éditions du Cerf, Paris 2012. Es significativo el hecho de que Matteo Nacci, profesor de la materia en la Pontificia Universidad Lateranense, mientras en una primera publicación había hablado de Ius Publicum (M. NACCI, Origini, sviluppi e caratteridel ius publicum ecclesiasticum, Lateran University Press, Città del Vaticano 2010), más tarde ha adoptado una titulación meramente descriptiva (M. NACCI, Chiesa e Stato dalla potestà contesa alla sana cooperatio. Un profilo storico-giuridico, Lateran University Press, Città del Vaticano 2015).

${ }^{4}$ La referencia es a: G. Dalla Torre, La città sul monte. Contributo ad una teoria canonistica delle relazioni fra Chiesa e Comunità politica, Ave, Roma ${ }^{1} 1996$ ('2007).

5 Sobre la problemática relativa a la categoría de la societas iuridice perfecta cfr. G. GHIRLANDA, Sociedad Jurídica Perfecta, en Diccionario General de Derecho Canónico, cit., vol. VII, 379 ss.

${ }^{6}$ Cfr. por ejemplo L. SPINELLI, Il diritto pubblico ecclesiastico dopo il Concilio Vaticano II. Lezioni di diritto canonico, en colaboración con G. DALLA TORRE, Giuffrè, Milano ${ }^{2} 1985,80$ ss.
} 
Mas, ¿es cierto verdaderamente que las metamorfosis o incluso el preconizado fin del Ius Publicum provengan exclusivamente de fuerzas endógenas, internas a la realidad eclesial?; ¿no es posible que sean (también) el fruto de la decadencia y del venir a menos de su contraparte, el mismo Estado moderno, con cuyo surgimiento y ascenso ha nacido tal disciplina, casi como contrapunto?

Sobre estos interrogantes queremos desarrollar algunas consideraciones.

\section{El ASCENSO del ESTAdo MOdeRnO...}

Hablar de Estado, o de Estado moderno, significa hacer referencia a una forma de organización de la comunidad política del todo peculiar, que no tiene precedentes históricos y que probablemente no tendrá un futuro idéntico a las experiencias que ahora quedan atrás. Dicho de otro modo, la historia humana, en sus diversos momentos y en sus diferentes culturas, ha conocido una multiplicidad de formas organizativas de la comunidad política; una de ellas, relativa a un periodo histórico determinado y a una realidad geopolítica concreta, es eso que llamamos Estado. El periodo histórico es el que parte de los siglos XIV-XV, por más que algunos elementos se puedan encontrar ya en la especulación política y jurídica medieval ${ }^{7}$; la realidad política es la europea, donde la idea de Estado se alimenta de presupuestos que se pueden encontrar en la cultura cristiana de los europeos, aunque también se trata de una idea y de una experiencia que se encuentra fuera del viejo continente, en las áreas civilizadas del mundo.

Como se ha afirmado, el elemento central de la diferenciación del Estado moderno respecto a otras formas de organización de la comunidad política consiste «en la progresiva centralización del poder según una instancia muy amplia, que termina por comprender el entero ámbito de las relaciones políticas». Más precisamente, «de este proceso, fundado a su vez sobre la concomitante afirmación del principio de la territorialidad de las obligaciones políticas y sobre la progresiva adquisición de la impersonalidad del orden político, a través de la evolución del concepto de officium, brotan los trazos esenciales de una nueva forma de organización política» ${ }^{8}$.

${ }^{7}$ M. Fumagalli Beonio Brocchieri, Il pensiero politico medievale, Laterza, Roma-Bari ${ }^{4} 2005$.

${ }^{8}$ P. SChIERA, Stato moderno, en Dizionario di politica, dirigido por N. Bobbio - N. MatTeucci, Utet, Torino 1976, 1006 ss. 
Se trata, naturalmente, de un proceso que se desarrolla en el devenir de la historia, en el interior del cual pueden distinguirse fases diversas que señalan progresivamente un nacimiento y un ascenso hasta la completitud (plenitud) de la configuración institucional. En cuanto aquí interesa, y con referencia al plano político-jurídico, se deben anotar algunos trazos esenciales de la organización que se institucionaliza.

En primer lugar, la soberanía, idea según la cual no existe otra autoridad ni otra ley por encima de lo que supra est: la idea, propia del Medievo, de una sociedad fuertemente jerarquizada en la que ninguna autoridad está desvinculada de una autoridad superior -también el Pontífice es Vicarius de Cristo, y como tal tiene poderes delegados y por ello limitados- es barrida del mapa. De la sobreposición de la autoridad eclesiástica a la civil, al fin, no queda rastro?.

En segundo lugar, la progresiva eliminación de la pluralidad de las fuentes del derecho, que habría caracterizado a la Edad Media, con la progresiva afirmación del monopolio de la fuerza legítima, reflejo de la concentración del poder. El derecho se reduce poco a poco a las leyes, cuya producción es a su vez reservada al Estado ${ }^{10}$. Al término de esta evolución, en el apogeo del Estado liberal decimonónico, el derecho canónico ha quedado fuera del ordenamiento jurídico estatal; incluso se pone en duda su propia juridicidad, al no ser un producto del legislador estatal ${ }^{11}$.

En tercer lugar, la afirmación cada vez más neta y rigurosa del principio de territorialidad como ámbito de expansión del poder político, pero también como límite de demarcación de la eficacia del derecho positivo. Como consecuencia, todo ordenamiento jurídico está cerrado territorialmente, pero es también autorreferencial. De aquí que el derecho secular y el canónico no son ya fuentes normativas que encarnan un único ordenamiento: el utrumque ius

${ }^{9}$ G. LE BRAs, La Chiesa del diritto. Introduzione allo studio delle istituzioni ecclesiastiche, introducción a la edición italiana de F. Margiotta Broglio, Il Mulino, Bologna 1976, 248.

10 Véanse al respecto las puntuales observaciones de P. GROssi, Giustizia come legge o legge come giustizia? Annotazioni di uno storico del diritto, en Mitologie giuridiche della modernità, Giuffrè, Milano ${ }^{3} 2007,15$ ss.

${ }^{11}$ Es conocido el irreflexivo e ideológicamente viciado juicio de Guido Padelletti, recogido en su discurso inaugural al curso de historia del derecho italiano en la Sapienza de Roma, en el cual afirmaba «ser el derecho canónico, en su aspecto técnico y formal, como en el sustancial y material, muy inferior a su fama»; ser en sustancia no otra cosa que «un edificio colosal pero barroco», cuya parte «predominante y original» estaría en definitiva en el «falso, inmoderado, incivil, inelegante» dato de la aportación de los pontífices en el curso de la historia (citado por V. DEL GIUDICE, Per lo studio del diritto canonico nelle Università italiane, en AA.Vv., Studi in onore di Francesco Scaduto, I, Cya, Firenze 1936, 205 ss.). 
de la Respublica Christiana; sino dos ordenamientos jurídicos externos el uno al otro, esto es, extraños entre sí.

Finalmente, la sujeción a la autoridad del Estado de las diversas formaciones sociales que expresaban la relacionalidad propia del hombre en una red compleja y articulada; una sujeción que llega bajo la Revolución francesa, con la ley Le Chapelier de 1791, a su supresión. Una desconfianza que no desaparecerá ni siquiera con el Estado liberal, el cual sólo de forma abstracta se hace paladín de las libertades, entre ellas la de asociación. La Iglesia, que se sustancia en una pluralidad de formaciones sociales, y en ciertos aspectos es una de las formaciones sociales que encarnan la sociedad civil, se ve plenamente afectada.

Es ambiguo, por tanto, el devenir del Estado moderno en sus relaciones con el fenómeno religioso y, señaladamente, con la Iglesia.

Por un lado, en efecto, se verifica la ruptura de la continuidad en el paso de los Estados confesionales católicos de los siglos XVII-XVIII a los Estados laicos (pero más a menudo laicistas), separadores, secularizados, de los siglos XIX-XX. Pero, por otra parte, se da una singular continuidad en la política y en la legislación estatal en materia eclesiástica, caracterizada por un robusto y penetrante jurisdiccionalismo: tanto el confesional de las monarquías del ancien régime como el aconfesional y laico de los Estados liberales. Porque, contrariamente a cualquier afirmación formal de separatismo y de laicidad, se mantiene una experiencia sustancialmente jurisdiccionalista. Una ambigüedad que, para nosotros los italianos, subyace sutilmente a la famosa fórmula del separatismo liberal del conde de Cavour, el gran artífice de la unidad de Italia, que hablaba de «Iglesia libre en el Estado libre» y no, como el programa en favor de la separación habría presupuesto, de «Iglesia libre y Estado libre» ${ }^{12}$.

En fin, como se ha dicho eficazmente a nivel histórico, «la modernidad nace de la dialéctica y de la ósmosis entre dos polos -en dialéctica o dualismoque encuentran su fundamento de modo diverso en el proceso de confesionalización. Iglesias y Estados están ligados en la vida y en la muerte en este proceso común» ${ }^{13}$.

12 Para el complejo caso del «Risorgimento» italiano cfr. C. CARDIA, Risorgimento e religione, Giappichelli, Torino 2011.

13 Así Paolo Prodi, en su artículo póstumo Senza Stato né Chiesa. L'Europa a cinquecenti anni dalla Reforma, Il Mulino, Bologna 2017, 1, 7. 
Como se comprende, han intervenido diversos factores para que se le planteara a la Iglesia, después de los tranquilizadores equilibrios nacidos de la medieval lucha de las investiduras, problemas bien determinados de defensa y de oposición.

\section{3 ...Y EL NACIMIENTO DEL IPEE}

El Ius Publicum Ecclesiasticum, lo sabemos, nace de aquí. Estudios muy cualificados, y que se remontan en el tiempo, han puesto en evidencia razones, tiempos, modalidades ${ }^{14}$.

En sustancia, ante un Estado moderno que pretendía someter a la Iglesia a su propia soberanía, ésta reacciona recolocándose -en su dimensión jurídico-institucional- fuera de la esfera jurídica estatal, tiende a emanciparse del jurisdiccionalismo confesional y más tarde del laico -ideológicamente opuestos, pero con el mismo abrazo sofocante-, recolocándose en una posición jurídica no ya de superioridad, pero sí de paridad. Una posición que se hace posible en la naciente sociedad internacional, por definición paritaria y no jerárquica, en la que los sujetos no están sometidos a la disciplina de un legislador superior, sino que está basada en el reconocimiento recíproco y en la común voluntad de dictarse normas a sí mismos a través de la actividad convencional.

Las proposiciones contenidas en la encíclica Immortale Dei de León XIII (1885) que, partiendo del axioma según el cual societates sunt uti fines se unen a la afirmación de una Iglesia como societas in proprio ordine máxima, del mismo modo que lo es el Estado en su orden, el secular, no son más que el punto de llegada de una evolución comenzada en la edad de la Contrarreforma utilizando fórmulas ya elaboradas por la canonística clásica, como aquella de la Ecclesia reipublicae comparatur, para llegar a afirmar con Roberto Belarmino que la Iglesia es «una comunidad de hombres tan visibles y palpables como la comunidad del pueblo romano, del reino de Francia o de la república de Venecia» ${ }^{15}$.

${ }^{14}$ Basta pensar en A. DE LA HERA - C. MOUNIER, Le droit public ecclésiastique à travers ses définitions, Revue di droit canonique 1 (1964) 32 ss.; pero cfr. también C. FANTAPPIE, Chiesa romana e modernità giuridica, t. I, L'edificazione del sistema canonistico (1563-1903), Giuffrè, Milano 2008, 65 ss.

15 De controversiis Christianae fidei, t. II, 1. III, c. II, 1601, coll. 137-138. No hace falta decir que con ello Belarmino no confundía completamente la Iglesia con el Estado, sino que quería decir que, desde el punto de vista jurídico, se presenta como una comunidad de hombres jurídicamente organizada, del mismo modo que ocurre con la comunidad política. 
Por tanto, respecto a las pretensiones jurisdiccionalistas de los Estados, razones de defensa de la libertas Ecclesiae y razones apologéticas, conjuntamente, habían favorecido la asimilación analógica de la figura jurídica de la Iglesia a la del Estado: de algún modo la Iglesia se presenta, según el viejo estilo del Ius publicum ecclesiasticum externum, como una entidad parangonable con los Estados.

Son exigencias externas a la institución eclesiástica las que imponen semejante reajuste, que lleva a reconducir -habría que decir a «reducir»- completamente la problemática de las relaciones con la autoridad política al interior de la perspectiva internacionalista. Partiendo del axioma de las societates uti fines, el magisterio y la doctrina canonística continuaron haciendo hincapié en que la Iglesia es superior al Estado, puesto que lo espiritual es superior a lo temporal; sin embargo, aceptaron que en el plano jurídico, en el internacional, ambas instituciones están en una posición de paridad ${ }^{16}$. Mas el derecho canónico no viene así determinado exclusivamente por sus relaciones ad extra; tal como he intentado aclarar en otra ocasión, todo el derecho canónico acaba por estar condicionado por las peculiares presentaciones fijadas por la nueva disciplina del Ius Publicum: también la codificación de 1917 (y en parte incluso la de 1983) es fruto de dichas presentaciones ${ }^{17}$.

Desde este punto de vista la actividad concordataria ${ }^{18}$, que se desarrolla de manera progresiva justamente en el paradigma internacionalista, se sostiene en el ordenamiento canónico interno por la reivindicación de los iura nativa Ecclesiae, una reivindicación repetida en diversos ámbitos de las competencias eclesiásticas que, si se vuelve a mirar con sensibilidad comparatista cuanto ocurre en las relaciones entre ordenamientos jurídicos estatales, no puede dejar de sorprender, en la medida en la que establece obligaciones jurídicas -en general abstenciones-, frente a sujetos externos y extraños al ordenamiento canónico, como son los Estados. Es evidente que la ratio de las disposiciones en que dicha reivindicación se contiene se entiende en función de la singularidad que marcan las relaciones entre Iglesia y Estado respecto a las relaciones

${ }^{16}$ Véanse al respecto las agudas observaciones de S. COTTA, I Concordati tra storia, politica e diritto, en G. Dalla Torre, I Concordati nel pensiero di Sergio Cotta, Aracne, Roma 2008, 51 ss.

17 Cfr. G. Dalla TORRE, L'esperienza novecentesca della codificazione canonica, en La Chiesa e gli Stati. Percorsi giuridici del Novecento, Studium, Roma 2017, 120 ss.

18 Sobre los desarrollos de la actividad concordataria después del Código de 1983, cfr. en particular J. Calvo Álvarez, Desarrollo del Derecho Concordatario después del CIC de 1983, Ius Canonicum 49 (2009) 347 ss. 
entre Estado y Estado: en estos últimos, de hecho, se distinguen netamente pueblo, territorio y soberanía, mientras en el caso de las relaciones entre Iglesia y Estado se verifica la existencia de dos soberanías sobre el mismo pueblo (al menos potencialmente) y sobre el mismo territorio.

Para las consideraciones que estamos desarrollando queda la singularidad de las formulaciones normativas, detrás de las cuales existe toda una vivencia histórica en la cual dichos iura Ecclesiae han sido repetidamente amenazados o incluso lesionados por los poderes políticos.

\section{UNA FORMA DE ORGANIZACIÓN DE LA COMUNIDAD POLÍTICA EN DECADENCIA}

Que la forma de organización de la comunidad política que llamamos Estado moderno está en declive es un fenómeno visible para todos. También de aquellos que no quieren mirar y que, en este Occidente de los inicios del nuevo siglo y del nuevo milenio, se baten patéticamente por una «recuperación de la soberanía de sus Estados» (el así llamado «soberanismo», como se dice con un feo neologismo ${ }^{19}$ ).

La decadencia de la forma-Estado se debe a diversas razones, pero en particular a dos: una de carácter factual, la otra ideológica.

La primera viene dada por el fenómeno, hoy bien conocido, de la globalización: un fenómeno de múltiples caras, de las cuales la preeminente y en ciertos aspectos absorbente es la económica. La globalización de los procesos, de las relaciones, de los intereses abaten progresivamente las fronteras: ningún Estado es ya una isla ni puede aislarse del resto del mundo, aunque lo quisiera ${ }^{20}$. La transnacionalidad de los fenómenos escapa al control de los Estados y, por consiguiente, a su reglamentación jurídica. La cerrazón y la autosuficiencia de los ordenamientos jurídicos estatales, con sus inderogables límites de orden público, es un recuerdo del pasado; derechos pertenecientes a familias jurídicas diversas se sobreponen y se confunden; renace un ius

${ }^{19}$ Cfr. G. Dalla Torre, Sovranismo, en Studium, 2017, 3.

20 El fenómeno es evidente también en un Estado pequeñísimo y del todo peculiar como es la Ciudad del Vaticano. No es casualidad que los Papas Benedicto XVI y Francisco hayan debido intervenir con una serie de leyes de materia penal y financiera: para algunas reflexiones al respecto cfr. R. ZANNOTTI, La normativa antiriciclaggio dello Stato vaticano, en Annali di diritto vaticano 2015, edición de G. Dalla Torre - P. A. BOnNET, Libreria Editrice Vaticana, Città del Vaticano 2015, 67 ss. 
mercatorum $^{21}$, por tanto no de origen estatal, mientras las jurisdicciones estatales son marginadas por el progresivo recurso a la jurisdicción privada, arbitral.

Con un cierto estupor estamos llegando a conocer fenómenos impensables hasta hace poco tiempo, como la ultraterritorialidad de las leyes y de las jurisdicciones, con aquel otro, conectado con el anterior, del crecimiento de las jurisdicciones concurrentes ${ }^{22}$.

En suma: la globalización abate los confines tradicionales, sustituyéndolos por fronteras diversas, mercantiles o religiosas. Pero la eliminación de la dimensión territorial que, en su esencia, es constitutiva del Estado moderno, es un factor y una señal del declive del Estado: por ello tiene perfecta razón el Papa Francisco cuando repite que el tiempo es superior al espacio, que es necesario generar cambios, activar cambios, más que proteger un territorio o defender el espacio propio ${ }^{23}$. Todo ello ha tenido un impacto muy fuerte en el terreno del derecho.

La otra razón del declive del Estado moderno, que he llamado ideológica, se encuentra en el fin del concepto de soberanía, sobre el que todo se construía.

El Estado es siempre menos soberano cuando se multiplican las instancias supranacionales e internacionales, con un poder siempre mayor de intervención en sus interna corporis; cuando se hacen añicos, en su interior, en los localismos renacientes, reacciones frente a la globalización con su tendencia a la homologación. Los fenómenos localistas, que conocemos bien en todos nuestros países, son también expresiones de reivindicaciones de la subsidiaridad frente a la centralización del Estado moderno; pero, a mi juicio, constituyen la reacción, a nivel de psicología social, al proceso de «homogeneización

${ }^{21}$ En relación con la actual «globalización jurídica», un gran historiador del Derecho ha hecho notar que uno de los fenómenos que hoy viene a agravar la crisis del Estado productor del derecho es el de la «privatización y fragmentación de las fuentes de producción del derecho», caracterizado por la «autoorganización de los entes privados, los cuales, por cuenta propia, gracias al trabajo de expertos privados, inventan instrumentos adecuados para ordenar sus tráficos jurídicos, dando vida a un canal jurídico que se afianza y discurre al lado del propio del Estado, previendo jueces privados cuyas decisiones los sujetos se obligan a observar» (P. GROssI, Prima lezione di diritto, Laterza, Roma-Bari 2003, 69 ss.).

22 Sobre este fenómeno véase N. PICARDI, La crisi del monopolio statuale della giurisdizione e la proliferazione delle Corti, en Corti europee e giudici nazionali, Bononia University Press, Bologna 2011, 5 ss.

${ }^{23}$ Véase, por ejemplo, la Ex. Ap. Evangelii Gaudium, nn. 22-23. El texto del documento puede leerse AAS (2013) 1019 ss. 
universal» inducido por la globalización: se redescubren las raíces propias para no perder la propia identidad.

Pero con el desarrollo de la teoría y de la práctica de los derechos humanos el Estado ya no es soberano, y no lo es por definición, antes que por procesos fácticos (o de hecho). El Rex no está ya legibus solutus; la suya es una autoridad limitada, porque cualquier derecho humano reconocido constituye un límite a la expansión de la voluntad política y del derecho estatal. En cierto sentido es verdad que ahora sólo el pueblo -o digamos principalmente el individuo- se ha convertido efectivamente en soberano.

Por otro lado se asiste a una deslocalización y pluralización de los poderes, que ya no están sometidos al tradicional: el poder político. Se emancipan de él el poder económico, el científico-tecnológico, el de los mass-media, que se colocan fuera del poder político y en una dimensión transnacional ${ }^{24}$.

A modo de conclusión se puede afirmar que es evidente que el Estado no desaparecerá, pero que será, al final de los procesos señalados, muy distinto del que habíamos conocido y heredado del pasado, manteniéndose como una suerte de simulacro si bien todavía titular de muchos poderes y funciones.

\section{LAS CONSIGUIENTES METAMORFOSIS DEL IPEE}

De ahí el interrogante: ¿desaparecerá el Ius Publicum Ecclesiasticum Externum con la desaparición de la forma de la comunidad política, como reacción a la cual había nacido?

En mi opinión pronosticar una desaparición sería por lo menos arriesgado; es distinto diagnosticar unas metamorfosis que, como ya se ha dicho, están ya en acto y son parcialmente visibles. Entre ellas me parece que hay que tener especialmente en cuenta las dos que siguen.

La primera se entrevé en la perspectiva interordinamental e internacionalista en la cual, como se ha dicho, durante siglos se presenta la vieja cuestión de las relaciones entre la Iglesia y los Césares de este mundo.

No es difícil observar cómo se produce un cambio de la acción internacional de la Santa Sede hacia el problema de la tutela de los derechos humanos, comenzando naturalmente por el de la libertad religiosa, que es el funda-

${ }^{24}$ Cfr. Introduzione a la sesión «Politica e potere» della 44 Semana social de los católicos italianos (Bolonia 2004), cuyas actas han sido publicadas en F. GARELLI - M. SimONE (eds.), La democrazia. Nuovi scenari nuovi poteri, Edizioni Dehoniane, Bologna 2005, cfr. en particular 305 ss. 
mento de todos, así como la tutela de la paz, que en el fondo no es otra cosa que un derecho del hombre ${ }^{25}$. La actividad concordataria ha venido dirigiendo cada vez más su propio focus de las libertates Ecclesiae, que es la razón de la institución, a la libertad religiosa, que es la razón del hombre, pertenezca o no a la Iglesia católica. En otro sentido se ha venido intensificando la actividad internacional de los Pontífices, entre otros a través de la adhesión cada vez más amplia de la Santa Sede -no sólo ni sobre todo para la Ciudad del Vaticano, sino para toda la Iglesia- a convenciones internacionales plurilaterales, como las de la tutela de la infancia, contra el tráfico de estupefacientes, contra la criminalidad en materia financiera, contra el terrorismo o la corrupción. Convenciones cuya ratio está, en definitiva, en la tutela del hombre, de su inalienable dignidad, en sus derechos irreprimibles.

Se trata de los desarrollos de las enseñanzas del Concilio Vaticano II, sobre todo aquella incluida en el párrafo 76 de la Constitución pastoral Gaudium et spes, según la cual la comunidad política y la Iglesia, independientes y autónomas la una de la otra en su propio campo, «están al servicio de la vocación personal y social de los mismos hombres».

Como se ha observado justamente, «a partir del Concilio Vaticano II, también la Iglesia católica, después de una reflexión larga y no carente de dificultades, se ha dotado de un cuadro normativo renovado para las relaciones que podríamos calificar como "externas"; con las demás religiones, con el Estado y, en fin, con la sociedad y la cultura de nuestro tiempo. No se ha tratado de un simple cambio de políticas, sino más bien de una auténtica renovación, hecha posible, como siempre ocurre en los procesos de reforma de la Iglesia, por una profunda reflexión teológica sobre su propia identidad. Todo ello le ha llevado a comprender de una manera nueva su propia relación con el mundo, en una fecunda tensión, que todavía experimentamos hoy, entre la evaluación de aquello de positivo que aporta la civilización moderna y un espíritu crítico respecto a lo que no parece coherente con el Evangelio y con la recta razón ${ }^{26}$.

Un segundo fenómeno que señala la metamorfosis en curso se presenta en el proceso de recuperación de una de las dimensiones dentro de las cuales

${ }^{25}$ Una profundización en G. DAlla TORRE, Pace e diritti umani nell'insegnamento di Giovanni Paolo II, Studium 1 (2004) 13 ss.

26 P. R. GALLAGHER, Libertà religiosa e diritti umani nell'Europa del XXI secolo. Non problema ma parte della soluzione, L'Osservatore Romano, 14 octubre 2015, p. 5. 
la cuestión de las relaciones entre Iglesia y comunidad política puede ser encuadrada, y que en los desarrollos históricos del Ius Publicum aparecía sustancialmente olvidada: aquélla de una Iglesia como pueblo de Dios que busca animar a los pueblos de esta tierra. Por tanto, no Iglesia y mundo, sino Iglesia en el mundo.

Esta perspectiva, que ha dominado la Edad Antigua y -si bien con la necesaria consideración de la peculiaridad del Sacrum Imperium - la Era Medieval, fue suplantada en la modernidad, por las razones ya señaladas, por otra más institucional.

Se trata de una perspectiva que ha sido revalorizada a partir del Concilio Vaticano II, el cual no por casualidad recuperó aquella joya de la literatura cristiana antigua constituida por la carta a Diogneto, en la que se afirma justamente que «los cristianos tienen en el mundo la misma función del alma en el cuerpo ${ }^{27}$. Las enseñanzas conciliares sobre la Iglesia como pueblo de Dios, sobre la animación cristiana del orden temporal, y en particular sobre la misión de los fieles laicos en la vida del mundo han estimulado un redescubrimiento y una nueva atención hacia una dimensión que en el curso de los siglos se había empañado ${ }^{28}$. El Magisterio pontificio posconciliar, principalmente sobre el laicado, ha desarrollado cada vez más la atención hacia un planteamiento que en cierto modo invierte la relación tradicional: no ya el Estado como dominus de la sociedad civil, sino ésta como la realidad hacia la cual las instituciones públicas y políticas, en varios niveles, están a su servicio. Y la Iglesia, en efecto, está en la sociedad, no en el Estado; las instituciones políticas son (deben serlo) laicas, pero la sociedad no lo es y no puede serlo.

Este cambio de perspectiva -no ya Iglesia y Estado, sino la Iglesia en la sociedad-conduce a una nueva perspectiva jurídica de las antiguas cuestiones en torno a las consecuencias de la distinción evangélica entre lo que es del Cé-

${ }^{27} \mathrm{Y}$ prosigue más tarde diciendo que «El alma se difunde en todos los miembros del cuerpo; también los cristianos están diseminados en las ciudades del mundo. El alma habita en el cuerpo, pero no es del cuerpo; también los cristianos habitan en el mundo, pero no son del mundo» [VI, 2-3; la traducción es de S. ZINCONE (ed.), A Diogneto, Borla, Roma $\left.{ }^{3} 1984,67\right]$. Significativamente, la carta a Diogneto es citada por el Concilio Vaticano II tanto en la Constitución dogmática sobre la Iglesia Lumen Gentium, n. 28, como en la Constitución sobre la divina revelación Dei Verbum, n. 4, como, en fin, en el decreto sobre la actividad misionera de la Iglesia Ad gentes, n. 15.

${ }^{28}$ Cfr. G. Dalla Torre, L'animazione cristiana del mondo, en Santità e mondo, Atti del Convegno teologico di studio sugli insegnamenti del beato Josemaría Escrivá (Roma, 12-14 ottobre 1993), Libreria Editrice Vaticana, Città del Vaticano 1994, 151 ss. 
sar y lo que es de Dios. Se trata de una perspectiva que del ordenamiento internacional desplaza la atención al interior de los ordenamientos seculares en los cuales, en diversos niveles, la sociedad civil se organiza; el problema es el de asegurar en ellos el respeto de la dignidad de la persona humana y de sus competencias irrenunciables, entre las cuales el derecho fundamental a la libertad religiosa, individual y colectiva, pero también institucional. Compete al pueblo de Dios actuar para reclamar ordenamientos jurídicos seculares cada vez más conformes a tales instancias, con una acción desde abajo de instancias y propuestas, capaz de obtener consensos y de ser una solicitud tan fuerte que no pueda ser ignorada. La desconfianza decimonónica por la democracia se transforma, por tanto, en amistad, precisamente porque ésta representa la forma de organización política que ofrece mayores seguridades al respeto de los derechos humanos.

A la luz de las anteriores consideraciones, parece evidente una de las razones profundas de la cada vez más acentuada atención del Magisterio a la temática de los derechos humanos: no se sale de su misión espiritual propia reduciéndola, en una lógica secularista, al coro de las agencias humanitarias; sino que toma una nueva senda para llegar sustancialmente a los objetivos perseguidos hasta ayer a través de la peculiar vía concordataria y con los límites consustanciales a ella, dado que se refieren exclusivamente a la Iglesia y a los católicos ${ }^{29}$. Y es interesante hacer notar que la misma actividad concordataria se ha venido desarrollando coherentemente, como se ha dicho, justo al comenzar de la cuestión nodal de los derechos de la persona humana.

Pero a todo ello se añade, en el momento presente, el denunciado fin del proceso dialéctico de ósmosis entre lo religioso y lo político que, se quiera o no, «ha sido un componente fundamental para la construcción del Estado de derecho y de la democracia ${ }^{30}$. Este final señala el ocaso del Estado moderno, señalando entre otras cosas «el fracaso de las más diversas políticas de multiculturalismo y de laicidad en las últimas décadas» ${ }^{31}$.

29 Observa Paolo Prodi que «el renacimiento del papado de la crisis conciliar, el "solsticio" de 1440, es bien conocido en sus dos fenómenos más aparentes; para salvar lo más posible su función universal se desarrolla una nueva relación centro-periferia que tiene su gozne no ya en la tradicional relación intraeclesial con las Iglesias particulares, sino en la relación política con los Estados: los instrumentos son los concordatos y las nunciaturas» (P. Prodi, Senza Stato né Chie$s a$, cit., 11).

${ }^{30}$ Cfr. de nuevo P. Prodi, Senza Stato né Chiesa, cit., 15.

${ }^{31}$ IDEM, o. c., 15. 


\section{Conclusiones}

Por tanto, no parece que estemos cerca del «canto del cisne» del Ius Publicum Ecclesiasticum; las consideraciones anteriores no parecen confirmar de ningún modo esta hipótesis. Pero es cierto que éste, tanto como doctrina como experiencia jurídica, vendrá a asumir progresivamente configuraciones nuevas, ulteriores, por más que -también es cierto- no podrán negar o superar a las tradicionales, heredadas del pasado, mas, si acaso, integrarlas.

El pontificado del Papa Francisco parece haber acentuado el proceso innovador. Como se ha hecho notar, «no es el registro diplomático en sentido clásico el que puede suministrar la clave interpretativa de la visión de la política mundial del Papa argentino. La cuestión central tiene que ver, más bien, con el papel global del Catolicismo, que el Papa Bergoglio impersona, interpreta, amplifica, enriquece con contenidos inéditos» ${ }^{32}$. Su magisterio en materia de derechos humanos y de nuevos derechos humanos, como los del ambiente, la casa común y la fraternidad universal, del papel positivo de las religiones en la sociedad, de la igualdad solidaria entre los pueblos, del fin del paradigma eurocéntrico del Estado, impone una reactualización del obrar de la Iglesia en el mundo.

Pero es sobre todo el modo de considerar el mundo, en el cual la Iglesia está llamada a obrar, el que impone una reorganización en primer lugar conceptual del Ius Publicum. Piénsese sólo en el principio según el cual «el tiempo es superior al espacio» ${ }^{33}$ o ese otro según el cual «el todo es superior a la parte ${ }^{34}$, sobre los que tanto insiste, para darse cuenta de las dimensiones y de las fronteras nuevas: no ya la concepción que ha caracterizado al Estado moderno, con sus dogmas de la territorialidad, de la estanqueidad, de la particularidad, sino la concepción de un movimiento en el devenir de la historia que tiene al mundo como escenario.

En particular en la Exhortación Apostólica Evangelii Gaudium hay un párrafo que, para lo que nos interesa, incita a pensar: «la paz social no puede entenderse como un irenismo o como una mera ausencia de violencia lograda por la imposición de un sector sobre los otros. También sería una falsa paz aquella que sirva como excusa para justificar una organización social que si-

\footnotetext{
32 P. Ferrara, Il mondo di Francesco Bergoglio e la política internazionale, presentación de P. Gentiloni, San Paolo, Cinisello Balsamo 2006, 21.

33 Evangelii Gaudium, nn. 222-225.

${ }^{34}$ Ibid., nn. 234-237.
} 
lencie o tranquilice a los más pobres, de manera que aquellos que gozan de los mayores beneficios puedan sostener su estilo de vida sin sobresaltos mientras los demás sobreviven como pueden. Las reivindicaciones sociales, que tienen que ver con la redistribución del ingreso, la inclusión social de los pobres y los derechos humanos, no pueden ser sofocadas con el pretexto de construir un consenso de escritorio o una efímera paz para una minoría feliz. La dignidad de la persona y el bien común están por encima de la tranquilidad de algunos que no quieren renunciar a sus privilegios. Cuando estos valores se ven afectados, es necesaria una voz profética» ${ }^{35}$.

En suma: la nueva visión del Papa Francisco parece acentuar la tarea profética de la Iglesia y, por tanto, también de su derecho y del Ius Publicum Ecclesiasticum Externum. Y ello parece reconectar precisamente con el último análisis de Paolo Prodi sobre el papel y la necesaria recuperación de la profecía, como clave peculiar de la relación entre la Iglesia y la potestad temporal en la historia de Occidente ${ }^{36}$.

Por tanto, se entrevé todo un trabajo, por hacer, para la reconceptualización de los esquemas tradicionales de una disciplina nacida con el nacimiento del Estado moderno. Será tarea de las más jóvenes generaciones de canonistas estar a la altura de semejante desafío.

35 Evangelii Gaudium, 24 de noviembre de 2013, n. 218.

${ }^{36}$ Veáse P. Prodi, Profezia, utopia, democrazia, en M. CACCIARI - P. Prodi, Occidente senza utopie, Il Mulino, Bologna 2016, 11 ss. 


\section{Bibliografía}

Belarmino, R., De controversiis Christianae fidei, t. II, l. III, c. II, 1601, coll. 137-138.

Calvo Álvarez, J., Cesaropapismo, en Diccionario General de Derecho Canónico, dirigido por J. Otaduy - A. Viana - J. Sedano, vol. II, Aranzadi, Cizur Menor 2012, 69 ss.

—, Desarrollo del Derecho Concordatario después del CIC de 1983, Ius Canonicum 49 (2009) 347 ss.

CARDIA, C., Risorgimento e religione, Giappichelli, Torino 2011.

COTTA, S., I Concordati tra storia, politica e diritto, en G. DALLA TORRE, I Concordati nel pensiero di Sergio Cotta, Aracne, Roma 2008, 51 ss.

Dalla Torre, G., Sovranismo, en Studium, 2017, 3.

—, L'esperienza novecentesca della codificazione canonica, en La Chiesa e gli Stati. Percorsi giuridici del Novecento, Studium, Roma 2017, 120 ss.

—, L'animazione cristiana del mondo, en Santità e mondo, Atti del Convegno teologico di studio sugli insegnamenti del beato Josemaría Escrivá (Roma, 12-14 ottobre 1993), Libreria Editrice Vaticana, Città del Vaticano 1994, 151 ss.

—, La città sul monte. Contributo ad una teoria canonistica delle relazioni fra Chiesa e Comunità politica, Ave, Roma ${ }^{1} 1996$ ('2007).

—, Pace e diritti umani nell'insegnamento di Giovanni Paolo II, Studium 1 (2004) 13 ss.

De la Hera, A. - Mounier, C., Le droit public ecclésiastique à travers ses définitions, Revue di droit canonique 1 (1964) 32 ss.

Del Giudice, V., Per lo studio del diritto canonico nelle Università italiane, en AA.Vv., Studi in onore di Francesco Scaduto, I, Cya, Firenze 1936, 205 ss.

FANTAPPIÈ, C., Chiesa romana e modernità giuridica, t. I, L'edificazione del sistema canonistico (1563-1903), Giuffrè, Milano 2008, 65 ss.

FERRARA, P., Il mondo di Francesco Bergoglio e la política internazionale, presentación de P. Gentiloni, San Paolo, Cinisello Balsamo 2006, 21.

Francisco, Ex. Ap. Evangelii Gaudium, nn. 22-23, AAS (2013) 1019 ss.

Fumagalli Beonio Brocchieri, M., Il pensiero politico medievale, Laterza, Roma-Bari ${ }^{4} 2005$.

GaLlagher, P. R., Libertà religiosa e diritti umani nell'Europa del XXI secolo. Non problema ma parte della soluzione, L'Osservatore Romano, 14 octubre 2015, p. 5. 
Garelli, F. - Simone, M. (eds.), La democrazia. Nuovi scenari nuovi poteri, Edizioni Dehoniane, Bologna 2005.

Ghirlanda, G., Sociedad Furídica Perfecta, en Diccionario General de Derecho Canónico, cit., vol. VII, 379 ss.

Grossi, P., Giustizia come legge o legge come giustizia? Annotazioni di uno storico del diritto, en Mitologie giuridiche della modernità, Giuffrè, Milano 32007, 15 ss.

—, Prima lezione di diritto, Laterza, Roma-Bari 2003, 69 ss.

GuzzetTi, G. B., Chiesa e política. Disegno storico, Marietti, Torino 1975.

LE BRAS, G., La Chiesa del diritto. Introduzione allo studio delle istituzioni ecclesiastiche, introducción a la edición italiana de F. Margiotta Broglio, Il Mulino, Bologna 1976, 248.

Leziroli, G., Stato e Chiesa. Per una storia del dualismo giuridizionale cristiano, Giappichelli, Torino 1991.

—, Relazioni fra Chiesa cattolica e potere politico, La religione come limite del potere, Giappichelli, Torino ${ }^{4} 1998$.

Minnerath, R., L'Église catholique face aux États. Deux siècles de pratique concordataire 1801-2010, Éditions du Cerf, Paris 2012.

NACCI, M., Origini, sviluppi e caratteridel ius publicum ecclesiasticum, Lateran University Press, Città del Vaticano 2010.

-, Chiesa e Stato dalla potestà contesa alla sana cooperatio. Un profilo storico-giuridico, Lateran University Press, Città del Vaticano 2015.

PICARDI, N., La crisi del monopolio statuale della giurisdizione e la proliferazione delle Corti, en Corti europee e giudici nazionali, Bononia University Press, Bologna 2011, 5 ss.

Prieto, V., Diritto dei rapporti tra Chiesa e società civile, Edizioni Università della Santa Croce, Roma 2003.

Prodi, P., Il Sovrano Pontifice. Un corpo e due anime: la monarchia papale nella prima età moderna, Il Mulino, Bologna 2006, 352.

—, Senza Stato né Chiesa, cit., 11.

-, Profezia, utopia, democrazia, en M. CACCIARI - P. PRODI, Occidente senza utopie, Il Mulino, Bologna 2016, 11 ss.

-, Senza Stato né Chiesa. L'Europa a cinquecenti anni dalla Reforma, Il Mulino, Bologna 2017, 1.

Saraceni, G., Chiesa e comunità política, Giuffré, Milano 1983.

SCHIERA, P., Stato moderno, en Dizionario di politica, dirigido por N. Bовbio N. MatTeucci, Utet, Torino 1976, 1006 ss. 
SpINELLI, L., Il diritto pubblico ecclesiastico dopo il Concilio Vaticano II. Lezioni di diritto canonico, en colaboración con G. Dalla TorRe, Giuffrè, Milano ${ }^{2} 1985,80$ ss.

ZANNOTTI, R., La normativa antiriciclaggio dello Stato vaticano, en Annali di diritto vaticano 2015, edición de G. DALla TORRE - P. A. BONNET, Libreria Editrice Vaticana, Città del Vaticano 2015, 67 ss.

Zincone, S. (ed.), A Diogneto, Borla, Roma ${ }^{3}$ 1984, 67. 
